\title{
Relations between organizational commitment and focal and discretionary behaviours
}

Pep Simo, Mihaela Enache, Jose M Sallan and Vicenc Fernandez

Department of Management, Universitat Politècnica de Catalunya, ETSEIAT.

Published online in the Service Industries Journal 19 Feb 2014. Vol 34, Num. 5, pp. 117

\begin{abstract}
The purpose of this paper is to analyse the relations between organizational commitment dimensions and two focal and discretionary behaviours (intention to stay and organizational citizenship behaviour). Drawing on a sample of 310 Spanish employees of small services firms, this research reveals that in contrast to recent findings that detected a non-linear (inverted U-shaped) relationship between continuance commitment and intention to stay, the form of the relationships between organizational commitment dimensions and the proposed outcomes is linear rather than non-linear. Furthermore, when dividing continuance commitment into two subcomponents, the research results indicate that the dimension associated with commitment based on few existing employment alternatives is significantly, negatively and linearly related to intention to stay and organizational citizenship behaviour. This suggests that the three-component model of organizational commitment suffers from a conceptual inconsistency, which is further discussed.
\end{abstract}


KEYWORDS: organizational commitment, intention to leave, organizational citizenship behaviour.

\section{INTRODUCTION}

Since the beginning of the 70's, the concept of organizational commitment has garnered increased interest in the literatures of organizational psychology and organizational behaviour (Mathieu \& Zajac, 1990), and has received a great deal of empirical and theoretical study. Although some researchers suggested that this concept is losing relevance (Baruch, 1998), it has been proven that organizational commitment is more important than ever, for both individuals and organizations (Mowday, 1998; Mathieu \& Zajac, 1990). From a global perspective, the society as a whole tends to benefit from employees' organizational commitment, in terms of lower rates of job movement and perhaps higher national productivity and work quality (Mathieu \& Zajac, 1990). Moreover, due to its high impact upon organizations, organizational commitment has acquired increased salience (Mathieu \& Zajac, 1990), which is reflected as well in a growing proliferation of recent studies focused on its antecedents, correlates, consequences and definitions (Meyer, Stanley \& Parfyonova, 2012; Meyer \& Maltin, 2010; Lapointe, Vandenberghe, Pannaccio, 2011; Fu, Deshpande \& Zhao, 2011; DeGieter, Hofmans \& Pepermans, 2011; Casper, Harris, Taylor-Bianco \& Wayne, 2011; Ehrhardt, Miller, Freeman \& Hom, 2011; Leow, 2011; Meyer, Stanley, Jackson, McInnis, Maltin \& Sheppard, 2011)

Far from closing this paradigm, researchers suggested new avenues for future research (Bergman, 2006; Luchak \& Gellatly, 2007) and new propositions (Solinger, van Olffen, \& Roe, 2008) that assure an extensive future research agenda. An interesting avenue for 
future research was presented by Luchak and Gellatly (2007), who opened a new path in the understanding of the relationships between organizational commitment and its consequences (e.g. job performance, intention to leave, absenteeism, organizational citizenship behaviour, etc.). They suggested that the form of the relationships between organizational commitment and its consequences can be nonlinear rather than linear. Furthermore, some researchers (Solinger et al., 2008) argued that the three-component model of organizational commitment (Meyer \& Allen, 1991), which has been the dominant model in organizational commitment research, is inconsistent, as it combines different attitudinal phenomena, with different relationships for focal and non-focal behaviours.

While many studies revealed that affective, continuance and normative facets of commitment are distinguishable components of organizational commitment, with different consequences upon behaviour, very few of them have tried to provide a rationale behind these differences. This research is aimed at analysing the form of relationships (i.e. linear and/or nonlinear) between the distinct dimensions of organizational commitment and two commonly studied work outcomes: on the one hand, the intention to stay in the organization (focal behaviour) and on the other, the organizational and individual dimensions of organizational citizenship behaviour (discretionary behaviour). 


\section{THEORY DEVELOPMENT AND HYPOTHESES}

\subsection{Conceptual framework}

Nowadays it is widely accepted in the literature that commitment is a force that binds an individual to an entity or course of action (Meyer \& Herscovitch, 2001). In the case of organizational commitment, the course of action is staying in the organization, thus being the focal behaviour. Several multidimensional models of organizational commitment have been recognized in the literature (e.g., (Allen \& Meyer, 1990; Angle \& Perry, 1981; Jaros, Jermier, Koehler, \& Sincich, 1993; O'Reilly \& Chatman, 1986; Penley \& Gould, 1988). However, the three-component model (Allen \& Meyer, 1990) can be regarded as the dominant model in organizational commitment research (Bentein, Vandenberghe, Vandenberg, \& Stinglhamber, 2005; Bergman, 2006; Cohen, 2003; Greenberg \& Baron, 2003). This model is rooted on the consideration that commitment comes in three distinct forms: affective attachment to the organization, perceived costs of leaving it, and a felt obligation to stay. These three forms, labelled affective, continuance, and normative commitment, respectively, are referred to as components of organizational commitment. Affective commitment was defined as employees' emotional attachment to, identification with, and involvement in the organization. Continuance commitment was conceptualized as the perception of cost associated with leaving the organization; and normative commitment refers to employees' feelings of obligation to remain with the organization. Researchers have explored the possibility that continuance commitment actually consists of two subdimensions: commitment reflecting high (personal) sacrifices and low (perceived) alternatives respectively (McGee and Ford, 1987; Powell and Meyer, 2004). High 
sacrifice relates to those factors that would be given up or disrupted by leaving the organization, while low alternatives refer to lack of perceived opportunities outside of the firm.

With respect to behavioural outcomes, affective commitment has been found to be positively related to a variety of work outcomes (e.g., job performance, organizational citizenship behaviour, attendance, well-being), whereas the same relations withcontinuance commitmenthave been found to be negligible or even negative (Meyer, Stanley, Herscovitch, \& Topolnytsky, 2002). Nevertheless, as high levels of affective and continuance commitment have been both associated with decisions to stay in the organization, it has been argued that the association between organizational commitment and work outcomes clearly depends on the form of commitment being assessed (Gellatly, Meyer, \& Luchak, 2006; Luchak \& Gellatly, 2007).

Meyer et al. (2004) suggested that affective and continuance commitment are associated with different motivational mindsets that potentially shape how individuals express their commitment. Drawing upon this framework, Luchak and Gellatly (2007), proposed to analyze that "these different motivational states result in fundamentally different kinds of relations, and that an assumption of the linearity in the case of continuance commitment underestimates its true relations with behavioural criteria” (Luchak \& Gellatly, 2007: 786). Based on Meyer et al.’s (2004) theoretical development, which was mainly rooted on the self-determination theory (Deci \& Ryan, 1985; Ryan \& Deci, 2000) and the regulatory focus theory (Higgins, 1997, 1998), Luchak and Gellatly (2007) proposed and empirically tested linear and non-linear relations between affective and continuance commitment and three commonly studied work outcomes. Their 
research results replicated linear models of organizational commitment and their results were consistent with previous research findings, indicating that affective commitment is more strongly related to work outcomes than is continuance commitment(Meyer et al., 2002). However, when introducing a quadratic continuance commitment term in the equation, they obtained different results, supporting the hypothesis that the form of the relationship between continuance commitment and different work outcomes is nonlinear, rather than linear. In particular, they observed that the intensity of the relationship grew slower for high levels of continuance commitment than for lower ones. In that sense, they argued that future research devoted to contrast the form of relationship between continuance commitment and other outcomes and to extend their empirical findings would have notable implications for human resource management policies and practices (Luchak \& Gellatly, 2007). However, these considerations should be taken with caution, due to the limitations associated with Luchak and Gellatly's (2007) study, on the one hand, and on the other hand, due to the recent conceptual critique offered to the three-component model of organizational commitment (e.g., Solinger et al., 2008).

Solinger, Offen and Roe (2008)'s conceptual critique to the three-component model argued that the model suffers from conceptual inconsistency and therefore should be retained to predict only employee turnover. They used the attitude-behaviour model to posit that affective commitment can be understood as an attitude towards the organization, while the normative and continuance dimensions are attitudes regarding specific forms of behaviour, which affect only focal outcomes, such as staying or leaving. Therefore, according to that model all dimensions of organizational commitment will be related to turnover, while only the affective dimension will be an 
antecedent of non-focal outcomes. Thus, a deeper analysis could provide a more global perspective.

Furthermore, the study of Luchak and Gellatly (2007) has several limitations. Their research was based on Meyer, Allen and Smith (1993)'s scales, without taking into consideration Powell and Meyer (2004)'s scale revision, which encompasses the two continuance commitment subcomponents developed by McGee and Ford (1998). Secondly, Luchak and Gellatly (2007) excluded from analysis the normative dimension of organizational commitment, and focus only on affective commitment and continuance commitment. Normative commitment is undoubtedly the most controversial component in Meyer and Allen’s (1991, 1997) model (Bergman, 2006) and various researchers did not considered it in their studies due to its relatively high correlation with other forms of commitment (Meyer et al., 2002). However, the exclusion of normative commitment produces bias in the empirical evaluation of the three component model.

This research uses the last version of Powell and Meyer's (2004) scales, which divide continuance commitment into two sub-dimensions (the first reflecting commitment based on few existing employment alternatives, and the second reflecting commitment based on personal sacrifice associated with leaving the organization). Furthermore, it includes into the analysis normative commitment, in an attempt to provide a more reliable analysis with respect to the three component model. More specifically, the aim of this research is to examine the form of the relation between the distinct dimensions and subcomponents of organizational commitment and (1) a focal behaviour - the 
intention to stay - and (2) a discretionary behaviour - organizational citizenship behaviour-. (see Figure 1)

\section{INSERT FIGURE 1 ABOUT HERE}

\subsection{Model and Hypotheses}

The extant literature suggested that employees with stronger affective commitment to an organization are expected to set more difficult goals and to achieve maximum level of accomplishment, due to their promotion focus (Luchak and Gellatly, 2007; Meyer et al., 2004). Hence, as affective commitment increases in strength, so will promotion focus and external regulation, and therefore individuals will experience an enhanced desire of fulfilling maximum level of accomplishment under the terms of commitment. This implies that the motivation associated with the intention to stay in the organization or to perform at high level will linearly increase, while turnover cognitions and absenteeism will linearly decrease.

In other words, the relation between affective commitment and focal behaviours is expected to be linear, and more specifically, positive in the case of individuals' intention to stay in the organization, and negative in the case of turnover cognitions. Furthermore, affective commitment is likely to have a positive, linear relation with those discretionary behaviours, which are favourable to the organizational interests (e.g., organizational citizenship behaviour toward individuals or toward the organization). The inclusion of a quadratic affective commitment term in the regression equation will not produce a significant increase in the coefficient of determination. Hence, it is expected that: 
H1a: Affective commitment has a positive, linear relationship with intention to stay.

H1b: Affective commitment has a positive, linear relation with citizenship behaviour directed toward the organization.

H1c: Affective commitment has a positive, linear relation with citizenship behaviour directed toward individuals.

It has been argued that the psychological state associated with continuance commitment is very different from the mindset associated with affective commitment (Luchak \& Gellatly, 2007). Continuance commitment consists of two components: the first is based on high personal sacrifices associated with leaving the organization, while the second is based on perceptions that few employment alternatives exist (Allen \& Meyer, 1990; McGee \& Ford, 1987; Meyer \& Allen, 1997). Thus, in both situations, when employees experience strong continuance commitment based on high sacrifices and/or strong continuance commitment based on low alternatives, they will be motivated by the need to remain with the organization. When employees perceive that alternative options are limited or that leaving the organization incurs high personal sacrifices, they will try to minimize the risks associated with leaving. Along these lines, Meyer et al. (2004) suggested that individuals with strong continuance commitment perceive their behaviour as externally controlled (external regulation) and will seek to satisfy minimum requirements for fulfilment (prevention focus).

These propositions, together with Luchak and Gellatly’s (2007) empirical findings show that when continuance commitment increases from low to moderate levels, employees’ perceived risk associated with leaving the organization is very low and will become 
increasingly more salient as employees need to adopt a defensive attitude. Therefore, they adopt a prevention focus to maintain security and safety. With this mindset in place, employees will be motivated to satisfy the minimum requirements for remaining in the organization: not being absent too often and performing job well-enough to avoid dismissal. Nevertheless, when employees experience high continuance commitment, the incremental effects of continuance commitment on behaviour tend to be modest or negligible, due to the fact that external regulation governing behaviour or driving the need to adopt a defensive focus will be maintained or will become less salient once the minimum requirements responsible for that behaviour have been satisfied.

With regard to focal behaviours (intention to leave or intention to stay), Luchak and Gellatly (2007)'s results show that as continuance commitment increases, the intention to leave decreases; however, this decrease is not linear, as stagnation occurs beyond moderate levels of continuance commitment. In other words, as employees experience stronger continuance commitment, the intention to leave decreases, but it is limited to a certain level, thus implying a non-linear relation. Similarly, continuance commitment should have a non-linear relation with intention to remain with the organization.

Therefore, it is expected that:

H2a: Continuance commitment reflecting high personal sacrifices has a positive, nonlinear relationship with the intention to stay.

H2b: Continuance commitment reflecting lack of alternatives has a positive, non-linear relationship with the intention to stay. 
In relation to positive discretionary behaviours, as continuance commitment increases from low to moderate levels, according to regulatory focus theory (Higgins, 1997), the need for a prevention focus to maintain security, safety and personal responsibility will also increase (Meyer et al. 2004). This defensive, self-oriented attitude may prevent individuals experiencing continuance commitment from exhibiting citizenship behaviours; however, beyond moderate levels of continuance commitment, the effects of continuance commitment upon behaviour tend to be negligible, as prevention mechanisms become less important once minimum requirements responsible for that behaviour have been met (Luchak and Gellatly, 2007); therefore, the relation between continuance commitment and organizational citizenship behaviour is expected to be non-linear, that is for low to moderate levels of both dimensions of continuance commitment, the negative relationship with organizational citizenship behaviour is expected to be stronger than for high levels of continuance commitment.

Based on these assertions, it is predicted that:

H2c: Continuance commitment reflecting high personal sacrifices) has a positive, nonlinear relationship with organization-directed citizenship behaviour.

H2d: Continuance commitment reflecting high personal sacrifices has a positive, nonlinear relationship with individual-directed citizenship behaviour.

H2e: Continuance commitment reflecting lack of alternatives has a positive, non-linear relationship with organization-directed citizenship behaviour.

H2f: Continuance commitment reflecting lack of alternatives has a positive, non-linear relationship with individual-directed citizenship behaviour. 
Normative commitment is characterized by a mindset of obligation, reflecting both moral duty and indebted obligation (Meyer \& Parfyonova, 2010). Following selfdetermination theory (Ryan \& Deci, 2000), Meyer et al. (2004) suggested that employees experiencing normative commitment are likely to perceive goal acceptance as an obligation, thus they experience greater introjected regulation and a stronger prevention focus. As in the case of continuance commitment, it can be argued that as normative commitment increases from low to moderate levels, prevention focus is becoming increasingly salient for individuals, as well as their desire to maintain safety. However, when commitment rooted on obligation increases beyond moderate levels, the need to adopt a defensive, prevention, focus is expected to become less salient for individuals, once the minimum requirements for fulfilment have been satisfied. Hence, it is expected that as normative commitment increases intention to leave increases too, but beyond a certain level commitment based on obligation will no longer increase motivation to stay, as prevention focus becomes less relevant for individuals. In the case of organizational citizenship behaviours, it is expected that employees with a high normative commitment should have little incentives to engage in acts of citizenship, as they their prevention focus will drive them satisfying the minimum job requirements. However, as prevention focus becomes less salient for individuals when normative commitment goes beyond moderate levels, the effects of this commitment mindset upon citizenship behaviours are modest or negligible. Therefore:

HЗa: Normative commitment has a positive, non-linear relationship with the intention to stay. 
H3b: Normative commitment has a positive, non-linear relationship with organizationdirected citizenship behaviour.

H3c: Normative commitment has a positive, non-linear relationship with individualdirected citizenship behaviour.

\section{METHOD}

\subsection{Sample}

Research data were collected using a web-based survey. The questionnaire was sent to 600 Spanish employees of small services firms. After one month, the questionnaire was closed, and 312 surveys were submitted by the respondents, representing a response rate of 52\%. After handling the missing data, 310 usable entries had been obtained (51.67\%).

The average age of the respondents (58.39\% women and $41.61 \%$ men) was 32.66 years old $(\mathrm{SD}=7.62)$. The average professional experience was 11.24 years $(S D=7.48)$, with an average organizational tenure of 6.11 years $(S D=6.40)$. The respondents on average worked for 3.69 organizations $(S D=2.43)$. They represented a diverse set of sectors: administration (18.39\%), financial (66.60 \%), education $(9,2 \%)$ and health (5.81) In terms of the higher level of education achieved, the distribution was the following: high-school (38.70\%), Bachelor’s degree (31.60\%) technical degree (16.12\%), master degree (7.10\%) and $\mathrm{PhD}(6.48 \%)$. 


\subsection{Measurement}

Organizational commitment was measured using the scales developed by Meyer, Allen and Smith (1993), taking into account the modifications suggested by Powell and Meyer (2004). That is, OC was assessed using a 7-points Likert scale, with 6 items for measuring affective commitment and normative commitment. Moreover, taking into consideration the contributions of McGee and Ford (1987) and Powell and Meyer (2004), continuance commitment was divided into two sub-dimensions. Continuance commitment based on high personal sacrifice associated with leaving the organization was measured using Powel and Meyer's (2004) 6-items scale. Continuance commitment based on limited or non-existent alternative options was assessed using Powel and Meyer’s (2004) 3-items scale.

The behaviours associated with organizational commitment were measured using the scales developed by Colarelli (1984) and Williams and Anderson (1991). The intention to stay was assessed using Colarelli's (1984) scale (sample item: "If I have my own way, I will be working for this organization one year from now”) and respondents were asked to express their level of agreement or disagreement with the 3 items on a 7-point scale ranging from 1 (strongly disagree) to 7 (strongly agree).

With respect to organizational citizenship behaviour, this research adopts Williams and Anderson (1991)'s two-dimensional model, which is one of the most accepted models in the literature (Vigoda-Gadot, Beeri, Birman-Shemesh, \& Somech, 2007). Each dimension, namely organizational citizenship behaviour directed toward the individuals and organizational citizenship behaviour directed toward the organization was also measured using a 7-point scale. These scales were reduced to ten items, five for each 
dimension, in order to avoid an excessive length of the survey and in an attempt to assure a reasonable response time. Along the line with other studies in this area, the criteria for the scale reduction were their factor loadings, (Gellatly et al., 2006), based on Williams and Anderson (1991)'s factor analysis. Demographic and background characteristics included in this study were: age, gender, and organizational tenure.

Data of this research was collected by means of a questionnaire sent to the sample study. The original questionnaire items were constructed in English and had to be translated into Spanish, the general language of the target population. To ensure the accuracy of the translation, a back-translation procedure was followed (Nunnally \& Bernstein, 1994). Moreover, seven cognitive interviews were conducted in order to ensure an accurate interpretation of the questionnaire items, as this technique allows understanding how respondents perceive and interpret questions, and to identify potential problems that may arise in prospective survey questionnaires (Drennan, 2003).

\section{RESULTS}

\subsection{Test of validity and reliability}

The internal consistency of the scales was measured by means of alpha Cronbach coefficients (see Table 1). The reliability analysis performed for the three components of organizational commitment produced alpha coefficients comprised between 0.841 and 0.932. These results are consistent with previous studies, such as Powell and Meyer (2004)-0.84- or Luchak and Gellatly (2007)-0.83; 0.87; 0.83-. Similarly, when comparing alpha coefficients for intention to stay, previous research indicated an internal consistency of approximately 0.73 (Colarelli, 1984; Gellatly et al., 2006). In the 
present study, an alpha of 0.851 was obtained. The organizational citizenship behaviour scales obtained a slightly lower, yet acceptable alpha coefficient (alpha for organizational citizenship behaviour directed towards the organization: 0.737 and alpha for organizational citizenship behaviour directed towards the individuals: 0.770 ) that were surprisingly of the same magnitude as those reported for the fuller, longer versions of the scale (Williams and Anderson, 1991), namely 0.71 for organizational citizenship behaviour directed towards the organization and 0.78 for organizational citizenship behaviour directed towards the individuals.

\section{INSERT TABLE 1 ABOUT HERE}

We conducted a confirmatory factor analysis with AMOS to test the bi-dimensional structure of continuance commitment and organizational citizenship behaviour. With regard to continuance commitment, results indicate that the two factor model fitted our data reasonably well $\left(\chi^{2}=104, \mathrm{df}=26\right.$; $\left.\mathrm{RMSEA}=.09, \mathrm{CFI}=.94, \mathrm{TLI}=.92\right)$ The competing one factor measurement model did not fit our data $\left(\chi^{2}=463\right.$, $\mathrm{df}=27$; $\mathrm{RMSEA}=.23$, $\mathrm{CFI}=.66$, TLI=.55). Subsequently, a confirmatory factor analysis was performed to test the two-factor model of organizational citizenship behaviour and the results show that the fit indexes fell within an acceptable range $\left(\chi^{2}=118, \mathrm{df}=34\right.$; RMSEA=.09, CFI=.89, TLI=.86). The one-factor measurement model of organizational citizenship behaviour did not fit our data: $\left(\chi^{2}=363\right.$, $\mathrm{df}=35$; RMSEA=.17, CFI=.59, TLI=.47). Furthermore, affective and normative commitment were factor analyzed to confirm that they are separate dimensions of organizational commitment, as some investigators have questioned the utility of retaining normative commitment as a separate scale (e.g., Ko, Price, \& Mueller, 1997), due to the strong correlation between these forms of 
commitment. The results indicate that the two factor model fitted reasonably well our data $\left(\chi^{2}=160, \mathrm{df}=53\right.$; RMSEA=.08, CFI=.96, TLI=.95), while the one factor model did $\operatorname{not}\left(\chi^{2}=520, \mathrm{df}=54 ; \mathrm{RMSEA}=.17, \mathrm{CFI}=.83, \mathrm{TLI}=.79\right)$.

In addition, as all measures were grouped in the same measurement instrument, the possibility of a common method bias was checked using Harman's one-factor test. Factor analysis did not identify any single factor that explained variance across all items, suggesting that mono-method bias is unlikely. Of the seven factors that are identified, the principal factor explains $28.45 \%$ of the variance. Due to the fact that no single factor is found to explain more than $50 \%$ of the variance, the data of the study can be accepted as valid (Podsakoff and Organ, 1986).

\subsection{Hierarchical regression analysis}

The next step involved hierarchical regression analyses to test the hypothesized relationships. First of all, the empirical study involved testing four models in which the dependent variable was the intention to remain with the organization, as a proxy for the focal behaviour (staying in the organization). In the first model, control variables were introduced and in the second, the organizational commitment dimensions (affective commitment, normative commitment, continuance commitment based on high sacrifices, continuance commitment based on low alternatives). The third model involved higher order continuance commitment terms and the fourth, higher order affective and normative commitment terms.

Prior to analysis, checks of the theoretical assumptions underlying multiple regression were undertaken, including normality, linearity, and homoskedasticity. These 
assumptions were met and, hence, it can be asserted that multiple regression is quite robust to any violations. Finally, because test of higher order relationship can also contribute to multicollinearity, a process of centring predictor variables before squaring them was applied for reducing intercorrelation between the first order and second order terms of the same variable. The value inflation factors were less than 3 , and the tolerance values were higher than 0.1 , providing evidence that the variables were not collinear (Kleinbaum, Kupper, \& Muller, 1998). Finally, Durbin Watson coefficient is closer to 2, thus indicating no autocorrelation among errors.

The results of hierarchical regression models presented in Table 2 show how much additional variance in intention to stay was explained by the commitment components $\left(\Delta \mathrm{R}^{2}=0,437 ; \mathrm{p}<0,001\right)$, beyond what demographic variables and job characteristics explained. Nevertheless, when introducing second order continuance commitment terms, it can be noticed that only the coefficient associated to lack of alternatives was significant, yet the increase in adjusted coefficient of determination was not significant.

\section{INSERT TABLE 2 ABOUT HERE}

The hypothesis H1a predicting a positive, linear relation between affective commitment and intention to stay was fully supported, as the regression coefficient is positive and statistically significant. Moreover, the research results suggest that introducing a higher order commitment term in the equation does not improve the predictive power of this variable. This result is consistent with previous research findings based on the threecomponent model (Meyer et al., 2002). 
On the contrary, hypotheses $H 2 a$ and $H 2 b$ were not supported, indicating that the form of the relationship between both dimensions of continuance commitment and intention to stay is linear, rather than non linear. The introduction of quadratic commitment terms in the equation does not improve the predictive power of this variable. The same occurs with normative commitment, thus hypothesis $H 3 a$ was not supported either.

Furthermore, the $\beta$ coefficients for affective commitment and continuance commitment associated with high sacrifices are significant and positive, consistent with Powell and Meyer (2004)'s results. The most unexpected finding was related to continuance commitment associated with low alternatives, as in this case the $\beta$ coefficient was negative and statistically significant. This indicates that as an individual's perception that alternative options are limited or inexistent increases in strength, the intention to stay in the organization is low. This finding raises the question of whether continuance commitment based on low alternatives can be considered a commitment component, because previous research (Meyer et al., 2004; Meyer \& Herscovitch, 2001; Meyer et al., 2002) indicated that organizational commitment has a negative and significant relation with focal behaviours, among which intention to stay. In other words, if an employee is committed with his or her organization, he/she doesn't want to leave it.

In the second model, the dependent variable was citizenship behaviour directed toward the organization. Importance of organizational commitment in explaining citizenship behavior directed towards the organization can be demonstrated by examining the changes in $\mathrm{R}^{2}$ from step to step $\left(\Delta \mathrm{R}^{2}=0,071 ; \mathrm{p}<0.001\right)$. The $\beta$ coefficients for gender and continuance commitment associated to lack of alternatives are negative and statistically significant $(\mathrm{p}<0.05)$ and the regression coefficient for affective commitment 
is positive and significant $(\mathrm{p}<0.01)$. The non-significance of the quadratic terms in models 3 and 4, and the fact that these models have a non-significant change in $\mathrm{R}^{2}$, in relation to model 2, indicates that the addition of quadratic terms does not increase the significance of the model. Thus, the relationships between intention to stay and the dimensions of organizational commitment are linear, rather than nonlinear. Thus, hypothesis $H 1 c$ was supported, while hypotheses $H 2 d, H 2 f$ and $H 3 c$ were rejected.

\section{INSERT TABLE 3 ABOUT HERE}

Citizenship behaviour directed toward individuals, presented a linear adjustment; that is, when introducing second order commitment terms, the significance of the regression coefficients did not varied with respect to the linear model, albeit the coefficient of determination increased. With regard to organizational commitment components, only the $\beta$ coefficient for affective commitment is positive and statistically significant. Therefore, hypothesis $H 1 c$ was supported and hypotheses $H 2 c, H 3 c$ and $H 4 c$ were rejected.

\section{INSERT TABLE 4 ABOUT HERE}

To summarize, taking into account the limitations of our sample, which is representative only for a certain percentage of the wage-earning population, the research results indicate that the relations between the organizational commitment dimensions and certain focal and discretionary behaviours are linear, rather than non linear. Findings regarding continuance commitment associated with limited alternatives are of concern, and future research should be devoted to examining the relation between this commitment sub-dimension and work attitudes and behaviours. Moreover, the empirical 
findings support Solinger, Olffen and Roe (2008)'s theoretical critique to the ThreeComponent Model, which suffers from conceptual inconsistencies that will be further explained in the conclusions section.

\section{DISCUSSION AND CONCLUSION}

\subsection{Potential contributions}

The results of this study support and extend previous research in several significant ways. Contrary to our expectations, when dividing continuance commitment into two sub-components, the dimension associated with commitment based on few existing employment alternatives was significantly, negatively and linearly related to intention to stay and organizational citizenship behaviour towards the organization. At a conceptual level, it seems clear that affective commitment represents an attitude towards a target, whereas continuance and normative commitment reflect attitudes toward discontinuing the employment relationship, derived from the consequences perceived (Solinger et al., 2008). This could explain the negative relationship between the continuance commitment sub-dimension associated with the lack of alternatives and intention to stay. An employee with a strong continuance commitment may perceive the few existing employment alternatives as an individual threat, and therefore imagine the negative consequences associated with losing his or her job. This perception is likely to lead him or her to look for new employment opportunities or alternatives to reinforce job security, and thus, his or her intention to stay diminishes. Anyway, it seems clear that this construct does not assess an organizational commitment dimension. Therefore, future research should be devoted to examining its causes and consequences. 
With regard to the other two commitment dimensions (affective commitment and normative commitment), our research findings are consistent with Meyer et al. (2002) 's meta-analysis. More specifically, our research results indicate that affective commitment is positively related with intention to stay and the two dimensions of organizational citizenship behaviour, and negatively related with organizational counterproductive behaviours, and the relationships are linear. The continuance commitment dimension reflecting high personal sacrifice, which according to Powell and Meyer (2004) substitutes or improves the continuance commitment scale proposed by Meyer, Allen and Smith (1993), presented a linear and positive relationship with the intention to stay. Consistent with previous research findings (Meyer et al., 2002), this continuance commitment dimension did not reveal any significant relationship with organizational citizenship behaviour.

Normative commitment did not presented any statistically significant relationship with any of the outcomes, albeit its high correlation with affective commitment, that raised the question of their distinguishability, as recently remarked in the literature (Bergman, 2006). The research findings, some of them unexpected at the beginning of the study, reinforce Solinger, Olffen and Roe (2008)'s assertions, which consider that the threecomponent model of organizational commitment suffers from a conceptual inconsistency and hence, a lack of unequivocal empirical support. Research results highlighted that continuance commitment generally correlated slightly negatively or not at all with affective commitment (Meyer et al., 2002) and with important work related outcome variables, such as organizational citizenship behaviour or work performance (Meyer et al., 2002). In a recent meta-analysis Meyer et al. (2002) found that continuance commitment yielded correlations of 0.03 with job involvement, -0.07 with 
job satisfaction,-0.01 with organizational citizenship behaviour, and -0.07 with job performance. These results cast doubt on the convergent validity of continuance commitment (Solinger et al., 2008).

In response to McGee and Ford's (1987) criticism, Meyer et al. (2002), and Powell and Meyer (2004) proposed to modify the continuance commitment scale and retain only the items reflecting personal sacrifice associated with leaving the organization. Nevertheless, although this study draws on those new scales, it continues raising the same problems and even adding new ones. On the one hand, the continuance commitment dimension based on the lack of alternatives presented negative relationships with the outcomes that were expected to have a positive relationship with organizational commitment dimensions. That is, when individuals are organizationally committed, they do not want to leave their employing organization. This suggests that continuance commitment based on few existing employment alternatives does not measure organizational commitment, but rather individuals’ psychological projections regarding future (that is, future consequences of discontinuing employment). On the other hand, the findings associated with continuance commitment based on high perceived sacrifice are consistent with previous research based on Meyer, Allen and Smith’s (1993) six-items scale. Hence, the construct validity continues being in doubt.

The research results raised another inconsistency, related not only to the high correlation between normative and affective components, but also among affective and continuance dimensions. The positive correlation (0.671) found between normative and affective commitment is consistent with previous research (Meyer et al., 2002) (0.63). This high correlation between these constructs raised the question of their 
distinguishability (Bergman, 2006; Ko et al., 1997). This research shows that, in spite of the high correlation between the affective and normative dimensions of commitment, they have distinct relations with outcomes. While affective commitment is related with focal and non-focal behaviours, normative commitment only has significant relationships with the former. These results confirm the objections raised by Solinger et al. (2008) about the validity of the three-component model of commitment. Furthermore, when focusing on continuance commitment, research results also revealed high correlations with both affective and normative commitment (0.439 and 0.489, respectively) and hence, doubts related to the discriminant validity are added to those associated with the convergent validity.

\subsection{Practical implications}

Research results show that, regardless of gender, age or work experience, service firms can reduce employee turnover by applying human resource policies that promote affective bonds between the individual and the organization (inducing, therefore, high levels of affective commitment), or by emphasizing sacrifices associated with leaving the organization (inducing, thus, continuance commitment). One of the most important contributions of this research is that the human resources policies directed at making an employee aware of the perceived scarcity of employment opportunities elsewhere do not seem effective and they may even diminish their intention to remain in the organization.

In contrast, human resources policies and practices directed at enhancing and stimulating employees' affective commitment do lead to organizational citizenship 
behaviours. Workshops oriented at clarifying and communicating organizational values, philosophy and principles can be beneficial for strengthening affective bonds between employees and the organization. Moreover, providing organizational support and promoting a trusting climate can also enhance individuals' affective commitment with their employing organization.

\subsection{Limitations and future research directions}

There are several limitations associated with the present study. First, cross-sectional correlational designs impede conclusive inferences regarding relationships of causality among the study variables. In order to overcome this limitation, future research should use longitudinal designs that permit more pertinent conclusions regarding the causal direction of the observed relationships. Second, the use of a sample of employees of small service firms could limit the generalizability of the study findings. Therefore, future research might seek samples that are more heterogonous in terms of employing organization size or sector. Furthermore, as reflected in the study findings, future research should the nature of the continuance commitment component reflecting few employment alternatives. This research raises the question of whether this construct does not really constitute a commitment dimension. However, future research is needed for examining its causes and consequences.

An interesting avenue for future research is the examination of linear and non-linear relationships between organizational commitment and various work outcomes in distinct contexts, in order to find whether cultural dimensions have any influence upon these relationships. Finally, our research findings support Solinger, Olffen and Roe’s (2008) assertions. This indicates that the three-component model of organizational 
commitment, which has been regarded as the dominant model in organizational commitment research, suffers from a conceptual inconsistency and a lack of unequivocal empirical support. As a consequence, future research should be devoted to develop a new general model of organizational commitment, together with measuring instruments that allow a consistent quantification of the constructs. Some authors suggested applying Mowday et al.'s (1982) model, although the organizational commitment questionnaire (OCQ) should be previously revised and carefully examined, as it received the critique of producing inflated relationships with turnover (Meyer \& Allen, 1991; O'Reilly \& Chatman, 1986; Reichers, 1985). Therefore, we are possibly facing a new beginning in organizational commitment research; nevertheless the extant scales should not be ignored, as they might continue serving to assess certain work perceptions of the employees.

\section{References}

Allen, N. J., and Meyer, J. P. (1996). Affective, continuance, and normative commitment to the organization: An examination of construct validity. Journal of Vocational Behavior, 49:3, pp. 252-276.

Allen, N. J., and Meyer, J. P. (1990). The measurement and antecedents of affective, continuance and normative commitment to the organization. Journal of Occupational Psychology, 63:1, pp. 1-18.

Angle, H. L., and Perry, J. L. (1981). An empirical-assessment of organizational commitment and organizational-effectiveness. Administrative Science Quarterly, 26:1, pp. 1-14. 
Baruch, Y. (1998). The rise and fall of Organizational Commitment. Human Systems Management, 17:2, pp. 135-143.

Becker, H. S. (1960). Notes on the concept of commitment. American Journal of Sociology, 66:1, pp. 32-40.

Bennett, R. J., and Robinson, S. L. (2000). Development of a measure of workplace deviance. Journal of Applied Psychology, 85:3, pp. 349-360.

Bentein, K., Vandenberghe, R. J., Vandenberg, C., and Stinglhamber, F. (2005). The role of change in the relationship between commitment and turnover: A latent growth modeling approach. Journal of Applied Psychology, 90, pp. 468-482.

Bergman, M.E. (2006). The relationship between affective and normative commitment: review and research agenda. Journal of Organizational Behavior, 27:5, pp. 645663.

Casper, W.J., Harris, C.M., Taylor-Bianco, A., and Wayne, J. (2011). Work-family conflict, perceived supervisor support and organizational commitment among Brazilian professionals. Journal of Vocational Behavior, 79:3, pp. 478-501.

Cohen, A. (2003). Multiple commitment in the workplace: An integrative approach. Erlbaum: Mahwah, NJ.

Colarelli, S.M. (1984). Methods of Communication and Mediating Processes in Realistic Job Previews. Journal of Applied Psychology, 69:4, pp. 633-642.

Cook, J., and Wall, T. (1980). New work attitude measures of trust, organizational commitment and personal need non-fulfillment. Journal of Occupational Psychology, 53:1, pp. 39-52.

De Gieter, S., Hofmans, J., and Pepermans, R. (2011). Revisiting the impact of job satisfaction and organizational commitment on nurse turnover intention: An 
individual differences analysis. International Journal of Nursing Studies, 48, pp. 1562-1569.

Deci, E. L., and Ryan, R. M. (1985). Intrinsic motivation and self-determination in human behavior, New York: Plenum.

Drennan, J. (2003). Cognitive interviewing: verbal data in the design and pretesting of questionnaires. Journal of Advanced Nursing, 42:1, pp. 57-63.

Ehrhardt, K., Miller, J.S., Freeman, S.J. Hom, P.W. (2011). An examination of the relationship between training comprehensiveness and organizational commitment: Further exploration of training perceptions and employee attitudes, Human Resource Development Quarterly, 22:4, pp. 459-489.

Farrell, D., and Rusbult, C.E. (1981). Exchange variables as predictors of jobsatisfaction, job commitment, and turnover: The impact of rewards, costs, alternatives, and investments. Organizational Behavior and Human Performance, 28:1, pp. 78-95.

Fu, V., Deshpande, S.P., and Zhao X (2011). The impact of ethical behavior and facets of job satisfaction on organizational commitment of Chinese employees, Journal of Business Ethics, 104:4, pp. 537-543.

Gellatly, I.R., Meyer, J.P., and Luchak, A.A. (2006). Combined effects of the three commitment components on focal and discretionary behaviors: A test of Meyer and Herscovitch's propositions. Journal of Vocational Behavior, 69:2, pp. 331345.

Greenberg, J., and Baron, A.B. (2003). Behavior in organizations (8th ed.), Upper Saddle River, NJ: Prentice Hall. 
Higgins, E.T. (1997). Beyond pleasure and pain. American Psychologist, 52:12, pp. 1280-1300.

Higgins, E.T. (1998). Promotion and prevention: Regulatory focus as a motivational principle, In Zanna, M. P. (Ed.), Advances in experimental social psychology, 30, pp. 1-46, New York: Academic Press.

Hrebinia, L.G., and Alutto, J.A. (1972). Personal and role-related factors in development of organizational commitment. Administrative Science Quarterly, 17:4, pp. 555-573.

Jaros, S.J., Jermier, J.M., Koehler, J.W., and Sincich, T. (1993). Effects of continuance, affective, and moral commitment on the withdrawal process - An evaluation of 8 structural equation models. Academy of Management Journal, 36:5, pp. 951995.

Kleinbaum, D.G., Kupper, L.L., and Muller, K.E. (1998). Applied regression analysis and other multivariable methods, Boston: PWS-KENT Publishing Company.

Ko, J.W., Price, J.L., and Mueller, C.W. (1997). Assessment of Meyer and Allen's three-component model of organizational commitment in South Korea. Journal of Applied Psychology, 82:6, pp. 961-973.

Lapointe, E., Vandenberghe, C., and Pannaccio, A. (2011). Organizational commitment, organization-based self-esteem, emotional exhaustion and turnover: A conservation of resources perspective, Human Relations, 64:12, pp. 1609-1631.

Leow, K.L. (2011). The organizational commitment: The study of mentoring and leader-member exchange (LMX) among auditors in Malaysia-moderating effects of gender, Journal of Interdisciplinary Social Sciences, 6:1, pp. 123-146. 
Luchak, A.A., and Gellatly, I.R. (2007). A comparison of linear and nonlinear relations between organizational commitment and work outcomes. Journal of Applied Psychology, 92:3, pp. 786-793.

Mathieu, J.E., and Zajac, D.M. (1990). A review and metaanalysis of the antecedents, correlates, and consequences of organizational commitment. Psychological Bulletin, 108:2, pp. 171-194.

McGee, G.W., and Ford, R.C. (1987). 2 (or more) dimensions of organizational commitment: Reexamination of the affective and continuance commitment scales. Journal of Applied Psychology, 72:4, pp. 638-641.

Meyer J.P., and Maltin E.R. (2010). Employee commitment and well-being: A critical review, theoretical framework and research agenda, Journal of Vocational Behavior, 77:2, pp. 323-337.

Meyer, J.P., Allen, N.J., and Smith, C.A. (1993). Commitment to organizations and occupations - Extension and test of a 3-component conceptualization. Journal of Applied Psychology, 78:4, pp. 538-551.

Meyer, J.P., and Allen, N.J. (1984). Testing the Side-Bet theory of organizational commitment - Some methodological considerations. Journal of Applied Psychology, 69:3, pp. 372-378.

Meyer, J.P., and Allen, N.J. (1991). A three-component conceptualization of organizational commitment, Human Resource Management Review, 1:1, pp. 6189.

Meyer, J.P., and Allen, N.J. (1997). Commitment in the workplace: Theory, research, and application. Oaks, CA: Sage Publications. 
Meyer, J.P., and Herscovitch, L. (2001). Commitment in the workplace: Toward a general model. Human Resource Management Review, 11, pp. 299-326.

Meyer, J.P., Becker, T.E., and Vandenberghe, C. (2004). Employee commitment and motivation: a conceptual analysis and integrative model. Journal of Applied Psychology, 89:6, pp. 991-1007.

Meyer, J.P., Stanley, D.J., Herscovitch, L., and Topolnytsky, L. (2002). Affective, continuance, and normative commitment to the organization: A meta-analysis of antecedents, correlates, and consequences. Journal of Vocational Behavior, 61:1, pp. 20-52.

Meyer, J.P., Stanley, D.S., Jackson, T.A. , McInnis, K,J., Maltin, E.R., and Sheppard, L. (2011) Affective, normative, and continuance commitment levels across cultures: A meta-analysis, Journal of Vocational Behavior, In press (Available on-line)

Meyer, J.P., Stanley, L.J., and Parfyonova, N.M. (2012). Employee commitment in context: The nature and implication of commitment profiles, Journal of Vocational Behavior, 80:1, pp. 1-16.

Mowday, R. T., Porter, L. W., and Steers, R. M. (1982), Employee-organization linkages: The psychology of commitment, absenteeism, and turnover, New York: Academic Press.

Mowday, R.T. (1998). Reflections on the study and relevance of organizational commitment, Human Resource Management Review, 8:4, pp. 387-401.

Mowday, R.T., Steers, R.M., and Porter, L.W. (1979). Measurement of organizational commitment. Journal of Vocational Behavior, 14:2, pp. 224-247.

Nunnally, J.C. (1978). Psychometric Theory (2nd Ed ed.), New York: McGraw-Hill. 
Nunnally, J.C., and Bernstein, I. H. (1994). Psychometric Theory (3rd Ed ed.), New York: McGraw-Hill.

O'Brien, K.E., and Allen, T.D. (2008). The relative importance of correlates of organizational citizenship behavior and counterproductive work behavior using multiple sources of data. Human Performance, 21:1, pp. 62-88.

O'Reilly, C., and Chatman, J. (1986). Organizational commitment and psychological attachment - The effects of compliance, identification, and internalization on pro-social behavior. Journal of Applied Psychology, 71:3, pp. 492-499.

Penley, L.E., and Gould, S. (1988). Etzioni model of organizational involvement - A perspective for understanding commitment to organizations. Journal of Organizational Behavior, 9:1, pp. 43-59.

Podsakoff, P.M., and Organ, D.W. (1986), Self-reports in organizational research: problems and prospects, Journal of Management, 12:4, pp.531-44.

Powell, D.M., and Meyer, J.P. (2004). Side-bet theory and the three-component model of organizational commitment. Journal of Vocational Behavior, 65:1, pp. 157177.

Prestholdt, P. H., Lane, I. M., and Mathews, R.C. (1987). Nurse turnover as reasonde action: Development of a process model. Journal of Applied Psychology, 72:2, pp. 221-227.

Reichers, A.E. (1985). A review and reconceptualization of organizational commitment, Academy of Management Review, 10:3, pp. 465-476.

Ritzer, G., and Trice, H.M. (1969). Empirical study of Becker,H side-bet theory. Social Forces, 47:4, pp. 475-478. 
Ryan, R.M., and Deci, E. L. (2000). Self-determination theory and the facilitation of intrinsic motivation, social development, and well-being. American Psychologist, 55:1, pp. 68-78.

Schwartz, S.H. (1973). Normative explanations of helping behavior: Critique, proposal, and empirical test. Journal of Experimental Social Psychology, 9:4, pp. 349-364.

Schwartz, S.H., and Tessler, R.C. (1972). Test of a model for reducing measured attitude-behavior discrepancies. Journal of Personality and Social Psychology, 24:2, pp. 225-\&.

Solinger, O.N., van Olffen, W., and Roe, R.A. (2008). Beyond the three-component model of organizational commitment. Journal of Applied Psychology, 93:1, pp. 70-83.

Stebbins, R.A. (1970). Misunderstanding concept of commitment: Theoretical clarification. Social Forces, 48:4, pp. 526-\&.

Vigoda-Gadot, E., Beeri, I., Birman-Shemesh, T., and Somech, A. (2007). Group-level Organizational Citizenship Behavior in the education system: A scale reconstruction and validation. Educational Administration Quarterly, 43:4, pp. 462-493.

Wiener, Y. (1982). Commitment in organizational: a normative view. Academy of Management Review, 7, pp. 418-428.

Wiener, Y., and Vardi, Y. (1980). Relationships between job, organization, and career commitments and work outcomes: An integrative approach. Organizational Behavior and Human Performance, 26:1, pp. 81-96. 
Williams, L.J., and Anderson, S.E. (1991). Job-Satisfaction and Organizational Commitment as Predictors of Organizational Citizenship and in-Role Behaviors. Journal of Management, 17:3, pp. 601-617. 


\section{Tables and figures}

Figure 1: Overview of the proposed model

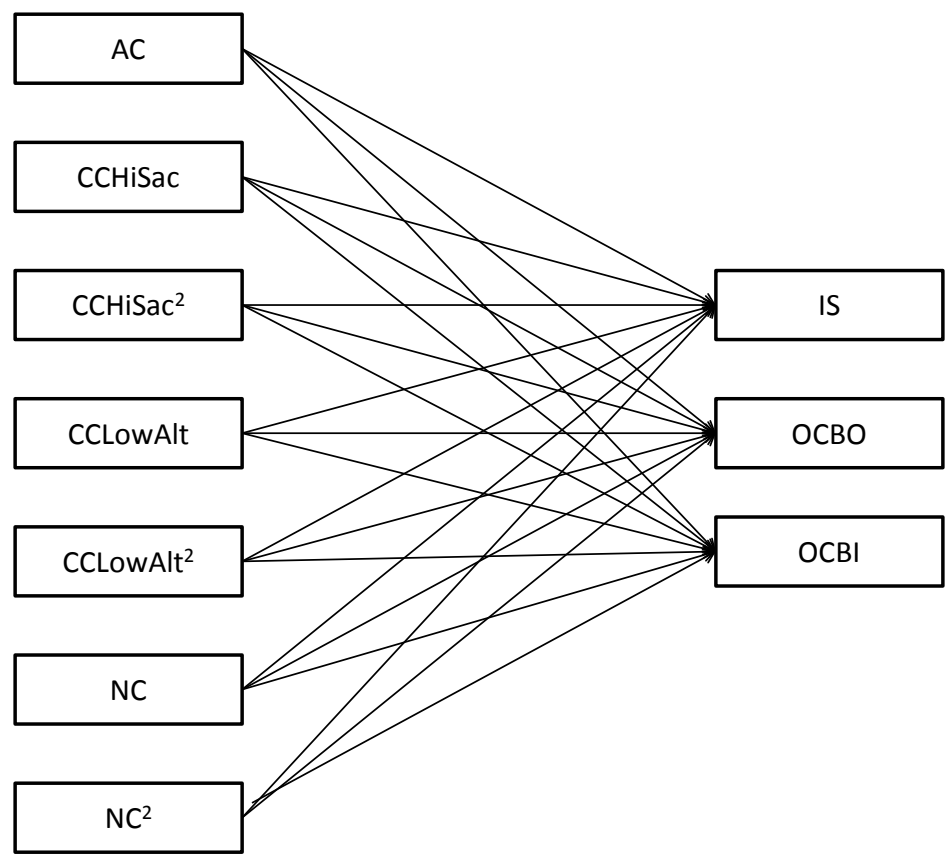


Table 1: Correlations, means, standard deviation, and Cronbach's alpha $\left({ }^{*} \mathrm{p}<.05\right.$,

$\left.{ }^{* *} \mathrm{p}<.01\right)$

\begin{tabular}{|c|c|c|c|c|c|c|c|c|c|c|}
\hline & Age & Gender & Tenure & $\mathrm{AC}$ & $\mathrm{NC}$ & CCLoAlt & CCHiSac & IS & OCBO & OCBI \\
\hline Age & & & & & & & & & & \\
\hline Gender & .096 & & & & & & & & & \\
\hline Tenure & $.686 * *$ & .053 & & & & & & & & \\
\hline AC & $.157^{* *}$ & .006 & $.218^{* *}$ & 0.932 & & & & & & \\
\hline $\mathrm{NC}$ & $.123^{*}$ & -.036 & $.123^{*}$ & $.672^{* *}$ & 0.880 & & & & & \\
\hline CCLoAlt & $.178^{* *}$ & $\begin{array}{l}.070 \\
\end{array}$ & $.236 * *$ & $-.123 *$ & $\begin{array}{l}.012 \\
\end{array}$ & 0.841 & & & & \\
\hline CCHiSac & $.116^{*}$ & .017 & $.255^{* *}$ & $.428 * *$ & $.481^{* *}$ & $.294^{* *}$ & 0.863 & & & \\
\hline IS & $.112^{*}$ & .073 & $.181^{* *}$ & $.585^{* *}$ & $.471^{* *}$ & $-.149^{* *}$ & $.513^{* *}$ & 0.851 & & \\
\hline OCBO & .016 & $-.119 *$ & .017 & $.211^{* *}$ & $.141^{*}$ & $-.164^{* *}$ & -.018 & $.157^{* *}$ & 0.737 & \\
\hline OCBI & -.057 & -.104 & -.024 & $.290 *$ & $.177 * *$ & -.067 & .035 & .104 & $.280 * *$ & 0.770 \\
\hline Mean & 32.65 & .42 & 6.11 & 26.80 & 21.15 & 9.25 & 20.56 & 13.96 & 29.07 & 29.37 \\
\hline SD & 7.62 & .49 & 6.40 & 9.18 & 8.94 & 4.77 & 8.34 & 5.48 & 3.56 & 3.56 \\
\hline
\end{tabular}

Note: The acronyms stand for: affective commitment (AC); normative commitment (NC); continuance commitment based on low alternatives (CCLoAlt); continuance commitment based on high personal sacrifices (CCLoAlt); IS: intention to stay; OCBO: organizational citizenship behavior directed towards the organization; OCBI: organizational citizenship behavior directed towards the organization 
Table 2: Results of hierarchical regression analyses of demographic factors and organizational commitment on intention to stay

\begin{tabular}{|c|c|c|c|c|}
\hline Variables & Model 1 & Model 2 & Model 3 & Model 4 \\
\hline Constant & $13.341^{* * *}$ & $13.099 * * *$ & $12.577^{* * *}$ & $12.622^{* * *}$ \\
\hline Age & -.022 & 011 & .013 & .014 \\
\hline Gender & .720 & .500 & .561 & .593 \\
\hline Tenure & 170 & .034 & .028 & .029 \\
\hline Affective commitment & & $.208^{* * *}$ & $.204 * * *$ & $.194^{* * *}$ \\
\hline Normative commitment & & .022 & .028 & .031 \\
\hline $\begin{array}{l}\text { Continuance commitment } \\
\text { based on low alternatives }\end{array}$ & & $-.268 * * *$ & $-.302 * * *$ & $-.306^{* * *}$ \\
\hline $\begin{array}{l}\text { Continuance commitment } \\
\text { based on high personal } \\
\text { sacrifices }\end{array}$ & & $.264^{* * *}$ & $.278^{* * *}$ & $.277^{* * *}$ \\
\hline $\begin{array}{l}\text { Continuance commitment } \\
\text { based on low alternatives } 2\end{array}$ & & & .027 & .028 \\
\hline $\begin{array}{l}\text { Continuance commitment } \\
\text { based on high personal } \\
\text { sacrifices }^{2}\end{array}$ & & & -.002 & -.001 \\
\hline Affective commitment ${ }^{2}$ & & & & -.002 \\
\hline Normative commitment ${ }^{2}$ & & & & .001 \\
\hline$\overline{\mathrm{R}^{2}}$ & .037 & .474 & .485 & .486 \\
\hline $\mathrm{R}^{2}$ adj. & .028 & .462 & .469 & .469 \\
\hline $\mathrm{F}$ & 3.939 & 38.910 & 31.341 & 28.253 \\
\hline$\Delta \mathrm{R} 2$ & $.037^{* * *}$ & $.437 * * *$ & .010 & .001 \\
\hline \multicolumn{5}{|c|}{$\mathrm{N}=310 ;$ Durbin-Watson $=2.043$} \\
\hline $.01 ; *$ & & & & \\
\hline
\end{tabular}


Table 3: Results of hierarchical regression analyses of demographic factors and organizational commitment on OCBO

\begin{tabular}{|c|c|c|c|c|}
\hline Variables & Model 1 & Model 2 & Model 3 & Model 4 \\
\hline Constant & $29.056 * * *$ & $29.187 * * *$ & $28.941 * * *$ & $28.878^{* * * *}$ \\
\hline Age & 011 & .006 & .003 & .001 \\
\hline Gender & $-.878 *$ & $-.927 *$ & $-.907 *$ & $-.834 *$ \\
\hline Tenure & .004 & -.011 & -.013 & -.013 \\
\hline Affective commitment & & $.079 * *$ & $.074 * *$ & $.073^{*}$ \\
\hline Normative commitment & & .015 & .020 & .012 \\
\hline Continuance commitment & & $-.095^{*}$ & $-.101^{*}$ & $-.100 *$ \\
\hline based on low alternatives & & & & \\
\hline Continuance commitment & & -.038 & -.043 & -.039 \\
\hline based on high personal & & & & \\
\hline sacrifices & & & & \\
\hline Continuance commitment & & & .005 & .004 \\
\hline based on low alternatives ${ }^{2}$ & & & & \\
\hline Continuance commitment & & & .003 & .003 \\
\hline based on high personal & & & & \\
\hline sacrifices $^{2}$ & & & & \\
\hline Affective commitment ${ }^{2}$ & & & & -.002 \\
\hline Normative commitment $^{2}$ & & & & .004 \\
\hline $\mathrm{R}^{2}$ & .015 & .086 & .093 & .100 \\
\hline $\mathrm{R}^{2}$ adj. & .005 & .065 & .066 & .067 \\
\hline F & 1.553 & $4.074 * * *$ & $3.410^{* * *}$ & $3.018^{* * *}$ \\
\hline$\Delta \mathrm{R} 2$ & .015 & $.071^{* * *}$ & .007 & .007 \\
\hline \multicolumn{5}{|c|}{$\mathrm{N}=310 ;$ Durbin-Watson $=1.933$} \\
\hline$* \mathrm{p}<0.01 ; *$ & & & & \\
\hline
\end{tabular}


Table 4: Results of hierarchical regression analyses of demographic factors and organizational commitment on OCBI

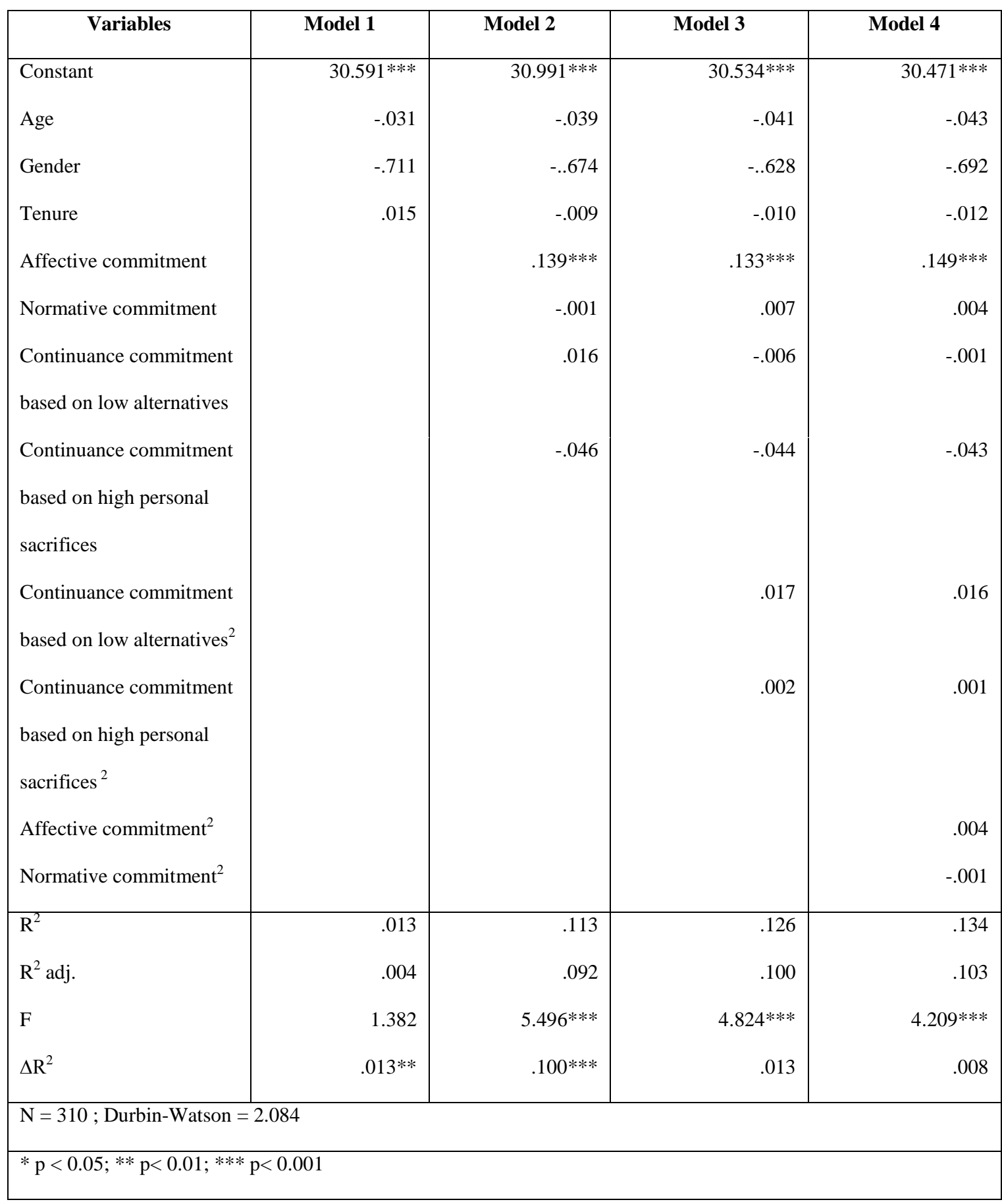

